\title{
rDNA ITS sequences of Uncinaria spp. from Tsushima leopard cat (Prionailurus bengalensis euptilura)
}

\author{
Y. SHIMONO ${ }^{1}$, S. TAHARAGUCHI ${ }^{2,3}$, K. TAIRA $^{4}$, N. MIYOSHI $^{1}$, N. YASUDA $^{1}$ \\ ${ }^{1}$ Department of Veterinary Pathology; ${ }^{2}$ Department of Veterinary Microbiology, Faculty of Agriculture, Kagoshima \\ University, 1-21-24 Korimoto, Kagoshima, Japan, 890-0065, E-mail: tsatoshi@azabu-u.ac.jp; \\ ${ }^{3}$ Department of Microbiology II; ${ }^{4}$ Department of Parasitology, School of Veterinary Medicine, Azabu University, \\ 1-17-71, Fuchinobe, Sagamihara, Kanagawa, Japan 252-5201
}

\begin{abstract}
Summary
Uncinaria spp. parasites were collected from two Tsushima leopard cats found on Tsushima Island, Nagasaki prefecture, Japan. One Uncinaria sp. was observed in the large intestines, and the other was observed in the small intestines. The nematode found in the large intestines was determined to be Uncinaria felidis by morphological identification. The other Uncinaria sp. found in the small intestines was morphologically different from U. felidis in the short-length of prevulvar flap. After isolation of genomic DNA of these worms, a second internal transcribed spacer (ITS2) of ribosomal DNA was amplified and sequenced using PCR techniques. The ITS2 region of $U$. felidis had 222 nucleotide sequences in length. The alignments of ITS2 sequence for Uncinaria felidis and Uncinaria $s p$. showed one nucleotide $(0.45 \%)$ replacement. These differrences may be regarded as intraspecific variation.
\end{abstract}

Keywords: Tsushima leopard; Uncinaria; Genomic DNA; ITS2

\section{Introduction}

Two species of Uncinaria were so far found in the Tsushima leopard cat (Prionailurus bengalensis euptilura) by morphometric investigations (Yasuda et al., 1992; Yasuda et al., 1993), but molecular investigations were not done yet. DNA sequencing techniques are nowadays being increasingly used to identify parasites species. The sequencing methods have often been performed on species differentiation of nematodes (Gasser et al., 1996; Chilton \& Gasser, 1999; Nadler et al., 2000; e Silva et al., 2006; Hu et al., 2002; Ishibashi, 2003; Otsuka et al., 2004; Mochizuki et al., 2006; Palmer et al., 2007). Of particular value was the development and establishment of sequencing method for ribosomal DNA (rDNA) isolated from fragments of worms and single egg of helminths (Gasser et al., 1993). Internal transcribed spacers (ITS) of rDNA were proposed to be useful target to identify the lineage of species of nematodes and to provide an accurate species marker (Otsuka et al., 2004, Mochizuki et al., 2006). The present study on Uncinaria nematodes was therefore focused on screening this genetic target.

\section{Materials and methods}

\section{Parasite isolation}

The parasites used in this study were detected from two Tsushima leopard cats that were killed in road accidents. One of leopard cats was obtained in November 2006 in Sago, Tsushima city, Nagasaki prefecture (CAT1). The second cat was acquired in January 2007 in Oshika (CAT2) that is about $12 \mathrm{~km}$ distance from Sago (Fig. 1). Parasites were isolated from intestinal contents under a stereomicroscope and were preserved in $70 \%$ ethanol at $-20{ }^{\circ} \mathrm{C}$. Five worms were collected in the large intestines (group herein denoted as "Worm A"), three worms were found in

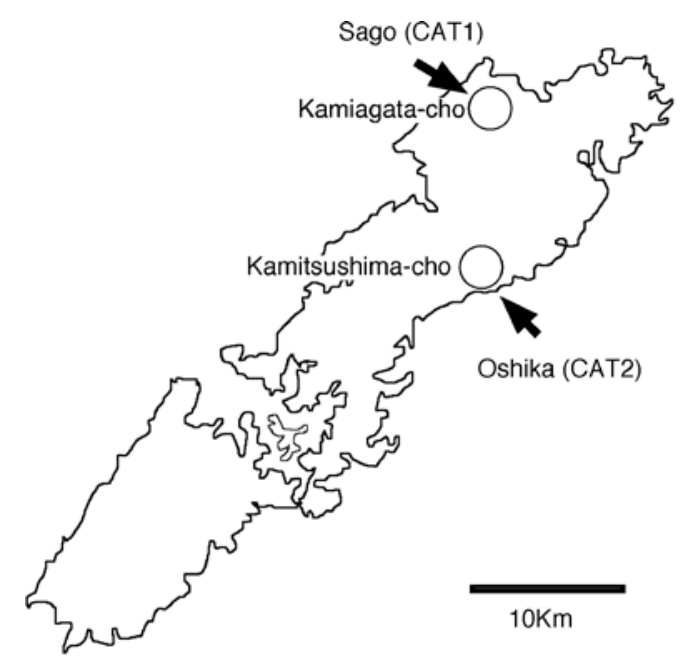

Fig. 1. Collection points of two dead Tsushima leopard cats (CAT1 and CAT2) on Tsushima Island, Japan 
Table 1. Parasites used in the study

\begin{tabular}{cccccc}
\hline Infected organ & $\begin{array}{c}\text { Sample } \\
\text { name }\end{array}$ & $\begin{array}{c}\text { PCR } \\
\text { product }\end{array}$ & ITS2 & $\begin{array}{c}\text { ID of Tsushima } \\
\text { leopard cat }\end{array}$ \\
\hline & & $3-2 \mathrm{HoL}$ & $312 \mathrm{bp}$ & & CAT2 \\
Worm A & Large intestine & $6-\mathrm{hooL}$ & $312 \mathrm{bp}$ & & CAT2 \\
& & $8-\mathrm{HoS}$ & $312 \mathrm{bp}$ & $222 \mathrm{bp}$ & CAT2 \\
& & $312 \mathrm{bp}$ & & CAT2 \\
& & $9-\mathrm{UM} 2$ & $312 \mathrm{bp}$ & & CAT1 \\
\hline \multirow{3}{*}{ Worm B } & \multirow{3}{*}{ Small intestine } & 3-2HoS & $312 \mathrm{bp}$ & & CAT2 \\
& & $9-4 \mathrm{UF}$ & $312 \mathrm{bp}$ & $222 \mathrm{bp}$ & CAT2 \\
& & $312 \mathrm{bp}$ & & CAT1 \\
\hline
\end{tabular}

the small intestines (group "Worm B") (Table 1). All worms were treated with lactophenol for morphological study under the microscope. Each worm was identified following the guidelines reported in Yasuda et al. (1992).

\section{rDNA ITS sequence}

Genomic DNA was isolated from a single worm by using DNeasy Blood \& Tissue Kits (Qiagen, Hilden, Germany) in accordance with the manufacture's protocol. The ITS2 region of the worm DNA was amplified using the following primers: NC1 (forward: 5'-ACG TCT GGT TCA GGG TTG TT-3'), and, NC2 (reverse: 5'-TTA GTT TCT TTT CCT CCG CT-3') (Gasser et al., 1993). The PCR products were purified using SUPREC ${ }^{\mathrm{TM}}$-02 (Takara, Shiga, Japan). The length of the PCR product from Uncinaria spp. isolated from the Tsushima leopard cats was $312 \mathrm{bp}$, this region was located between partial $5.8 \mathrm{~S}$ and $28 \mathrm{~S}$ rRNA genes. The lengths of the ITS2 were 222 bp (Fig. 4). The nucleotide sequences were determined by an automated DNA sequencer (ABI3130xl Genetic Analyzer; Applied Biosystems) using primers $\mathrm{NC} 1$ or $\mathrm{NC} 2$ in separate reaction with BigDye Terminator v3.1 Cycle Sequencing Kit (PE Biosystems). The sequences were aligned using the GENETYX Version 8.0 (GENETYX, Tokyo).

\section{Results}

Worm A had characteristics as follows. The smallest worm was about $4 \mathrm{~mm}$ in length. Worms had the anterior extremity inclined dorsally. The mouth was oval, armed with a pair of ventrolateral cutting plates and a pair of dorsolateral cutting plates. A female had a large prevulvar flap and terminal spike (Fig. 2). Based on characteristics described by Hasegawa (1989), the worm A was identified as Uncinaria felidis.

Worm B had characteristics as follows. The smallest worm was also about $4 \mathrm{~mm}$ in length. The mouth was oval, with
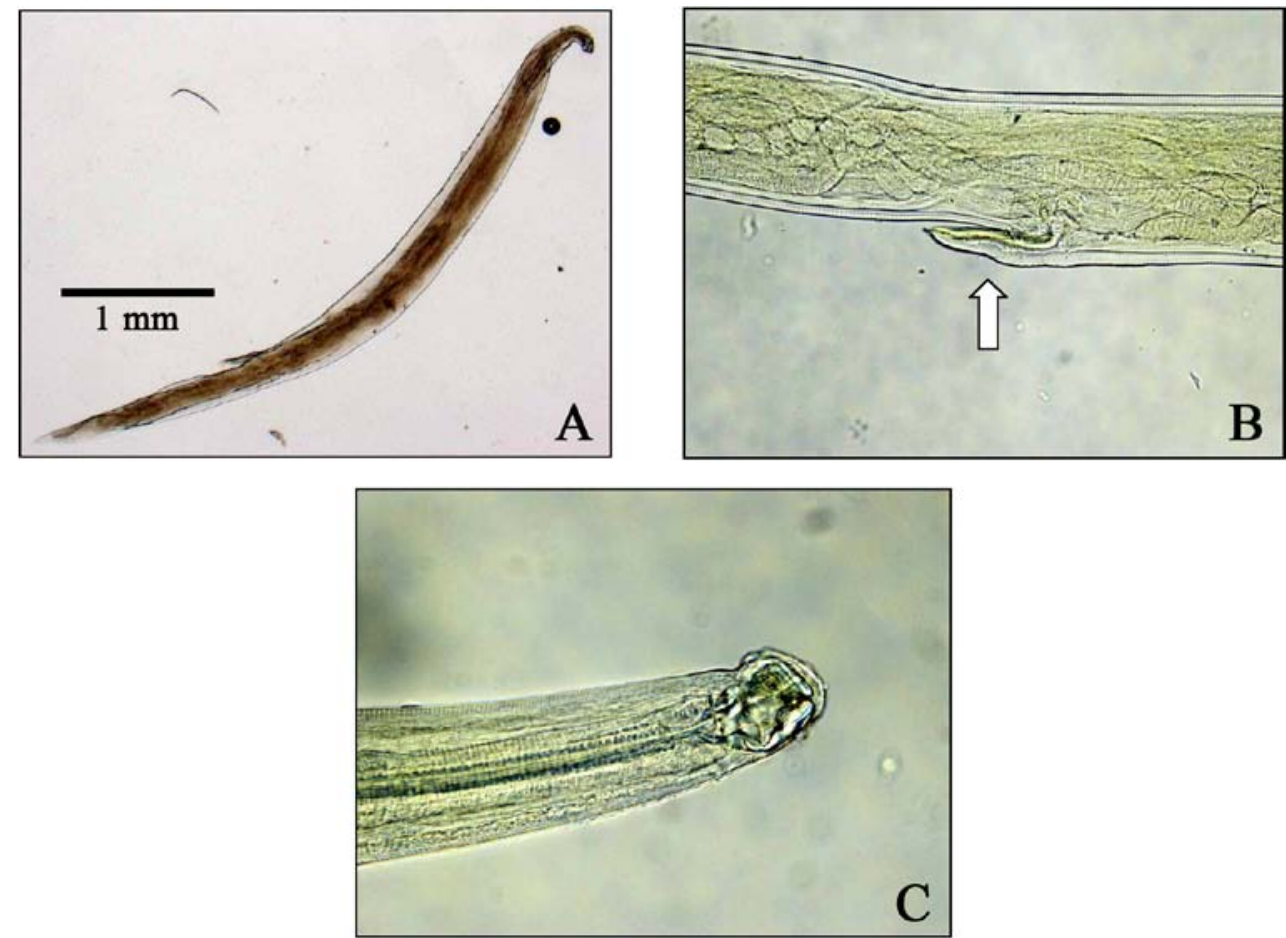

Fig. 2. Worm A photomicrographs 

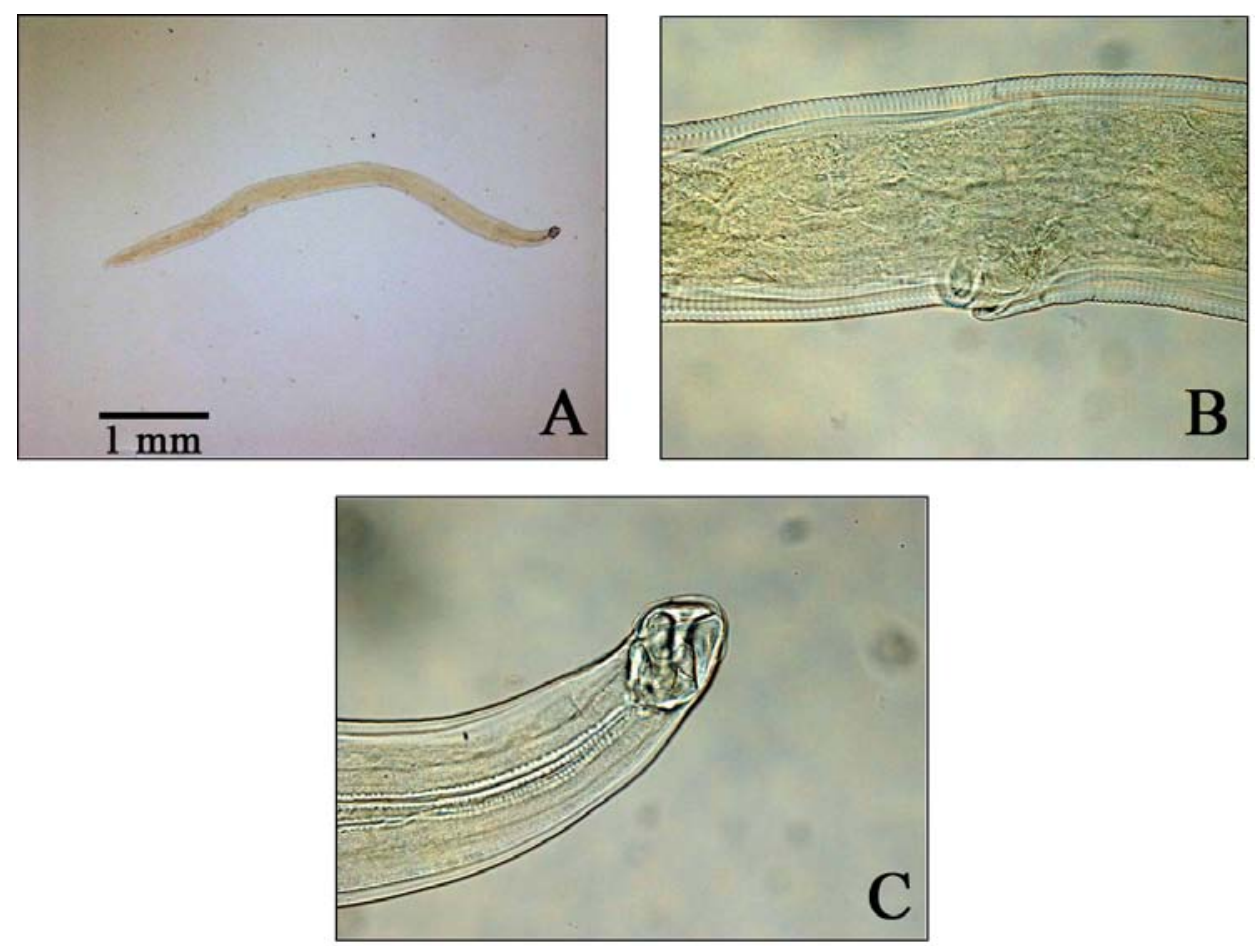

Fig. 3. Worm B photomicrographs

A - whole female worm body; B - short prevulvar flap; C - anterior end

a pair of ventrolateral cutting plates and a pair of dorsolateral cutting plates as in previous case. Female worms had a short prevulvar flap (Fig. 3). Worm B was morphologically closer to $U$. maya which was previously found in the small intestine of the Iriomote cat Prionailurus bengalensis iriomotensis, although U. maya is slightly smaller than Worm B in the body length (Hasegawa, 1989).

The 5' and 3' ends of ITS2 were determined by comparison with the ITS2 sequence of Ancylostoma duodenale (GenBank number: AJ001594). The obtained ITS2 sequences in examined isolates were compared with Uncinaria stenocephala from the arctic fox (AF194145), Uncinaria sp. from the California sea lion (AF217889) and Uncinaria sp. from the northern fur seal (AF217890), all originated from the U.S.A. The difference in the ITS2 sequence between Worm A and Worm B was associated only with one transitional nucleotide substitution G/A (i.e. in $0.45 \%$ of bases) (Fig. 4). The differences of ITS2 sequences between Worm A and Uncinaria stenocephala (AF194145), Uncinaria sp. from California sea lions (AF217889), Uncinaria sp. from northern fur seals (AF217890) were $12.9 \%, 15.0 \%$, and $14.2 \%$, respectively. The differences between Worm B and Uncinaria

Table 2. The ITS2 sequence differences comparing each sample with other Uncinaria sp. deposited in the GeneBank (\%)

\begin{tabular}{cccc}
\hline & $\begin{array}{c}\text { Uncinaria } \\
\text { stenocephala } \\
\text { (arctic fox: } \\
\text { AF19415) }\end{array}$ & $\begin{array}{c}\text { Uncinaria sp. } \\
\text { (California } \\
\text { sea lion: } \\
\text { AF217889) }\end{array}$ & $\begin{array}{c}\text { Uncinaria } \text { sp. } \\
\text { (northern } \\
\text { fur seal: } \\
\text { AF217890) }\end{array}$ \\
\hline Worm A & 12.9 & 15 & 14.2 \\
Worm B & 12.9 & 15.5 & 14.6 \\
\hline
\end{tabular}

stenocephala (AF194145), Uncinaria sp. from California sea lions (AF217889), Uncinaria sp. from northern fur seal (AF217890) were $12.9 \%, 15.5 \%$ and $14.6 \%$, respectively (Table 2). Among the five worms allocated to the Worm A set and the three worms allocated to the Worm B set, each ITS2 sequence had $100 \%$ homology.

\section{Discussion}

Given that a number of studies have demonstrated that ITS region provides accurate species markers, the intraspecific variation could be considered low in accordance with previous studies on this marker. The differences in the ITS2 sequences between $U$. stenocephala and Uncinaria spp. from the California sea lion and the northern fur seal were $12.4 \%$ and $11.6 \%$, respectively. The distance of the ITS2 sequence between Worm $\mathrm{A}$ and $U$. stenocephala gave the comparable value to that measured between $U$. stenocephala from arctic foxes and Uncinaria spp. from California sea lions and northern fur seal. Whereas the distance between Worm A and Uncinaria spp. from California sea lions and northern fur seals was slightly higher than that described above for $U$. stenocephala.

In comparison with Worm A, the ITS2 sequence of Worm B had one base pair difference (Fig. 4). Worm B differed from Worm A in the intestinal location of parasitizing, and also manifested clear differences in morphological features (Figs. 2, 3). The question thus arises over whether worm A and $\mathrm{B}$ may be regarded as taxonomically different individuals based on these differences. It is difficult to argue that the differences associated with biotope or cat affiliation induced the single base pair difference. U. maya para- 
Fig. 4. The alignment of the ITS2 sequence of worm A and worm B

sitizes in the small intestine of the Iriomote cat, and it closely resembles $U$. felidis that inhabits the large intestine of the Leopard cat (Hasegawa \& Asato, 1985; Hasegawa, 1989). However, U. maya is smaller in body length than $U$. felidis and the prevulvar flap of $U$. maya is shorter than that of $U$. felidis. Thus it has been proposed that $U$. felidis has transformed into U. maya with the replacement of the principal host, the Leopard cat into the Iriomote cat (Hasegawa et al., 1985; Hasegawa, 1989). In our study, the $0.45 \%$ difference in the ITS2 sequence between Worm B and Worm A (U. felidis) was recorded. Several published reports indicated that the differences up to $1 \%$ of ITS sequences could be regarded as attributable to intraspecific variation (Campbell et al., 1995; Romstad et al., 1997; Mochizuki et al., 2006). Thus we presume that Worm B originally belonged to the same species as Worm A $(U$. felidis), and as in the case of $U$. maya, it mutated from Worm A (U. felidis) due to adaptation to Tsushima leopard cats that evolved from Leopard cats.

Nadler et al. (2000) described differences between Uncinaria sp. from California sea lions and that from northern fur seals in molecular and morphometric characters. The authors stressed that not solely morphometric approach, but also molecular techniques are needed to unequivocally classify Uncinaria spp. However, the rate of sequence evolution varies according to the lineages, so it is needed to set a boundary, defining the minimum amount of sequence change that merits species status in individual nematode genera (Nadler et al., 2000). The data collected in the present study may contribute to the partial clarification of evolution in Uncinaria genus, but the more complex collection of sequence data in these organisms and from various nematode species are required to draw more precise conclusions.

In this study, the sequence data gave us suggestions about evolutionary relationships between the two morphologically different Uncinaria sp. from the Tsushima leopard cats. It will be of interest to further study this nematode in additional samples from other Tsushima leopard cats, and to compare the data gathered from parasites harboring by Iriomote wild cats and domestic cats.

\section{Acknowledgements}

We would like to thank the staff of The Tsushima Wildlife Center, Ministry of Environment, Japan for providing the samples of Tsushima leopard cats. The authors thank Mr. Gerald Larkins for checking the English text.

\section{References}

Campbell, A. J., Gasser, R. B. Chilton, N. B. (1995): Differences in a ribosomal DNA sequence of Strongylus species allows identification of single eggs. Int. J. Parasitol., 25: 359 - 365. DOI: 0020751994001166

Chilton, N. B., GASSER, R. B. (1999): Sequence differences in the internal transcribed spacers of DNA among four species of hookworm (Ancylostomatoidea: Ancy- 
lostoma). Int. J. Parasitol., 29: 1971 - 1977. DOI: S0020751999001484

E Silva, L. M., Miranda, R. R., SAntos, H. A., Rabelo, E. M. (2006): Differential diagnosis of dog hookworms based on PCR-RFLP from the ITS region of their rDNA. Vet. Parasitol., 140: 373 - 377. DOI: 10.1016/j.vetpar. 2006.04.012

Gasser, R. B., Chilton, N. B., Hoste, H., Beveridge, I. (1993): Rapid sequencing of rDNA from single worms and eggs of parasitic helminths. Nucleic Acids Res., 21: 2525 2526

GASser, R. B., StewArt, L. E.SPEARE, R. (1996): Genetic markers in ribosomal DNA for hookworm identification. Acta Trop., 62: 15 - 21. DOI: S0001706X96000150

HASEGAWA, H. (1989): Two new nematodes from the Iriomote cat, Prionailurus iriomotensis, from Okinawa: Uncinaria (Uncinaria) maya n. sp. (Ancylostomatoidea) and Molineus springsmithi yayeyamanus n. subsp. (Trichostrongyloidea). J. Parasitol., 75: 863 - 869

Hasegawa, H., Asato, R. N., Iwatsuki, K. M. (1985): Parasites of the Iriomote wildcat, Mayailurus iriomotensis(I). Isl. Stud. Okinawa, 3: 5 - 12

Hu, M., Chilton, N. B.GAsser, R. B. (2002): Long PCRbased amplification of the entire mitochondrial genome from single parasitic nematodes. Mol. Cell. Probes, 16: 261 - 267. DOI: S0890850802904226

ISHIBASHI, N. (2003): Biology of Nematodes (Japanese). Tokyo: University of Tokyo Press.

Mochizuki, R., Endoh, D., Onuma, M., Fukumoto, S. (2006): PCR-based species-specific amplification of ITS of Mecistocirrus digitatus and its application in identification

RECEIVED DECEMBER 28, 2010 of GI nematode eggs in bovine faeces. J. Vet. Med. Sci., 68: 345 - 351. DOI: JST.JSTAGE/jvms/68.345

NADLER, S. A., ADAMS, B. J., LyONS, E. T., DELONG, R. L., MELIN, S. R. (2000): Molecular and morphometric evidence for separate species of Uncinaria (Nematoda: Ancylostomatidae) in California sea lions and northern fur seals: hypothesis testing supplants verification. J. Parasitol., 86: 1099 - 1106

Otsuka, H., Onuma, M., Fukumoto, S., Mukai, T., ShirozU, A., ChiBA, T., AsakawA, M. (2004): Parasite identification based on the sequences of COX1 and ITS obtained from fecal eggs in an Asian tapir (Tapirus indicus). Jpn. J. Zoo Wildl. Med., 9: $31-37$

Palmer, C. S., Traub, R. J., Robertson, I. D., Hobbs, R. P., Elliot, A., While, L., Rees, R., Thompson, R. C. (2007): The veterinary and public health significance of hookworm in dogs and cats in Australia and the status of A. ceylanicum. Vet. Parasitol., 145: 304 - 313. DOI: 10.1016/j.vetpar.2006.12.018

Romstad, A., Gasser, R. B., Monti, J. R., Polderman, A. M., NAnsen, P., Pit, D. S.Chilton, N. B. (1997): Differentiation of Oesophagostomum bifurcum from Necator americanus by PCR using genetic markers in spacer ribosomal DNA. Mol. Cell. Probes, 11: 169 - 176. DOI: S0890850896900948

YASUdA, N., AKUZAWA, M., MARUYAMA, H., IZAwA, M., DOI, T. (1993): Helminths of the Tsushima leopard cat (Felis bengalensis euptilura). J. Wildl. Dis., 29: 153 - 155

YASUdA, N., MARUYAMA, H., AKUZAwa, M., IzAwa, M., MiYOSHI, N., SHIMIZU, T. (1992): A helminthological survey on Tsushima leopard cats, Felis bengalensis euptilura. Bull. Fac. Agric. Kagoshima Univ., 42: 45 - 58 